\title{
Ning Liu \\ Hongshiyan Landslide Dam Danger Removal and Coordinated Management
}

\begin{abstract}
This paper takes an overview of the Hongshiyan landslide dam triggered by an earthquake near Ludian County in Zhaotong City, Yunnan Province, introduces how the danger removal plan is drafted and implemented, and analyzes the outcome of its implementation. The paper then explains the significance and effect of coordinated management in the event of natural disasters and other public safety emergencies, and discusses ways to improve coordinated management.
\end{abstract}

Keywords: the Zhaotong Ludian earthquake, danger removal of the landslide dam, coordinated management

\section{Introduction}

At 16:30 on August 3, 2014 local time, a 6.5-magnitude earthquake hit Ludian County in Zhaotong City, Yunnan Province. The earthquake triggered rock-slides on both mountain sides near Hongshiyan Village sitting along Niulan River, damming the river and flooding the Hongshiyan hydro-power plant upstream. The landslide dam was located at $8.2 \mathrm{~km}$ southwest of Longtoushan Township in Ludian County, the epicenter, and was on the mainstream of Niulan River that flowed through Lijiashan Village in Huodehong Township of Ludian County and Hongshiyan Village in Baogunao Township of Qiaojia County. The dam body was about 600 $\mathrm{m}$ downstream the intake dam of Hongshiyan hydro-power plant.

Field inspections and aerial surveys by drones of the dam body revealed the urgency and difficulty of eliminating the dangers incurred by the landslide dam. In general, the Hongshiyan landslide dam was characterized by its huge size, great peril, extreme difficulty and complexity (see Figure 1).

(1) Huge size. The Hongshiyan landslide dam body took the shape of a saddle, high on two sides and low in the mid-

Manuscript received August 28, 2014; accepted September 15, 2014

Ning Liu (更)

The Ministry of Water Resources of the People's Republic of China, Beijing 100053, China

Email: liuning@mwr.gov.cn dle. The elevation of the saddle top was $1,216 \mathrm{~m}$; the dam body was about $83 \mathrm{~m}$ to $96 \mathrm{~m}$ high; its total volume reached $1.2 \times 10^{7} \mathrm{~m}^{3}$ and the volume of the dammed lake is about $2.6 \times 10^{8} \mathrm{~m}^{3}$. In other words, it was a large landslide dam. Aftershocks caused new rock-slides now and then on the right bank, raising the dam top elevation to $1,222 \mathrm{~m}$ and the total volume to $1.7 \times 10^{7} \mathrm{~m}^{3}$ (see Figure 2). The water level within the dammed lake was over $70 \mathrm{~m}$ higher than that in the river channel downstream; the catchment area covered 12,000 $\mathrm{km}^{2}$, and the maximum length of backwater was $25 \mathrm{~km}$. According to relevant national standards, Hongshiyan landslide dam was categorized as extremely perilous and Level I risky, both in the top categories.

(2) Great peril. The water level in the dammed lake rose fast, and in the directly threatened area there were many villagers, large land and several power plants. The water level rose by $0.6 \sim 0.8 \mathrm{~m}$ per hour in the initial stage of the dammed lake, and would be overflowing and crushing the barrier in two days. 1,015 villagers in two towns of Huize County upstream were directly affected; over 30,000 villagers and 2,201 hectares of farm land in altogether ten towns of Ludian, Qiaojia and Zhaoyang County downstream were directly threatened; and Tianhuaban and Huangjiaoshu hydro-power plants were also put at risk. Niulan River was in the main flood period, threatening heavy rainfall that would quickly raise the water level (see Table 1). The dammed lake was like a pool hanging over the head of the people downstream, and would wreak huge havoc with the life, property and hydro-power infrastructure downstream once it collapsed.

(3) Extreme difficulty. To take engineering measures for danger removal, the earthquake destroyed roads must be resumed in no delay so that large equipment could be transported to the landslide dam. In order to resume the road to the dam body downstream on the left bank, a bridge must be carved and built on a cliff; in order to resume the road to the dam body upstream on the right bank, there were two kilometers of road that could only use ferrying raft; the mountain sides, particularly the $600 \mathrm{~m}$ high steep mountain side on the right bank, still collapsed constantly due to aftershocks and rainfall, posing great safety risks to the field work. Moreover, 
in order to build the emergency discharge channel, huge safety risks were taken during times of field inspection at the powerhouse of Hongshiyan hydro-power plant and the access tunnel on the right bank, and several plans were drafted. In short, in the initial stage of the Hongshiyan landslide dam, inaccessible roads, constant rock-slides, insufficient data and unclear field situation constituted huge obstacles to emergency treatment (see Figure 3).

(4) Field operation complexity. The dam body was locat- ed in a deep valley flanked by steep mountain slopes, where the topographic slope was of $35^{\circ} \sim 60^{\circ}$. Some parts were escarpment unsuitable for machinery operation; moreover, the operation procedure on the dam body was complex since the boulders had to be detonated before large machinery could work. In addition, the river surface upstream the dam body was strewn with floatage, jeopardizing transportation. Therefore, a clean-up team was needed. Teams working on emergency treatment, material supply and logistics, etc. had

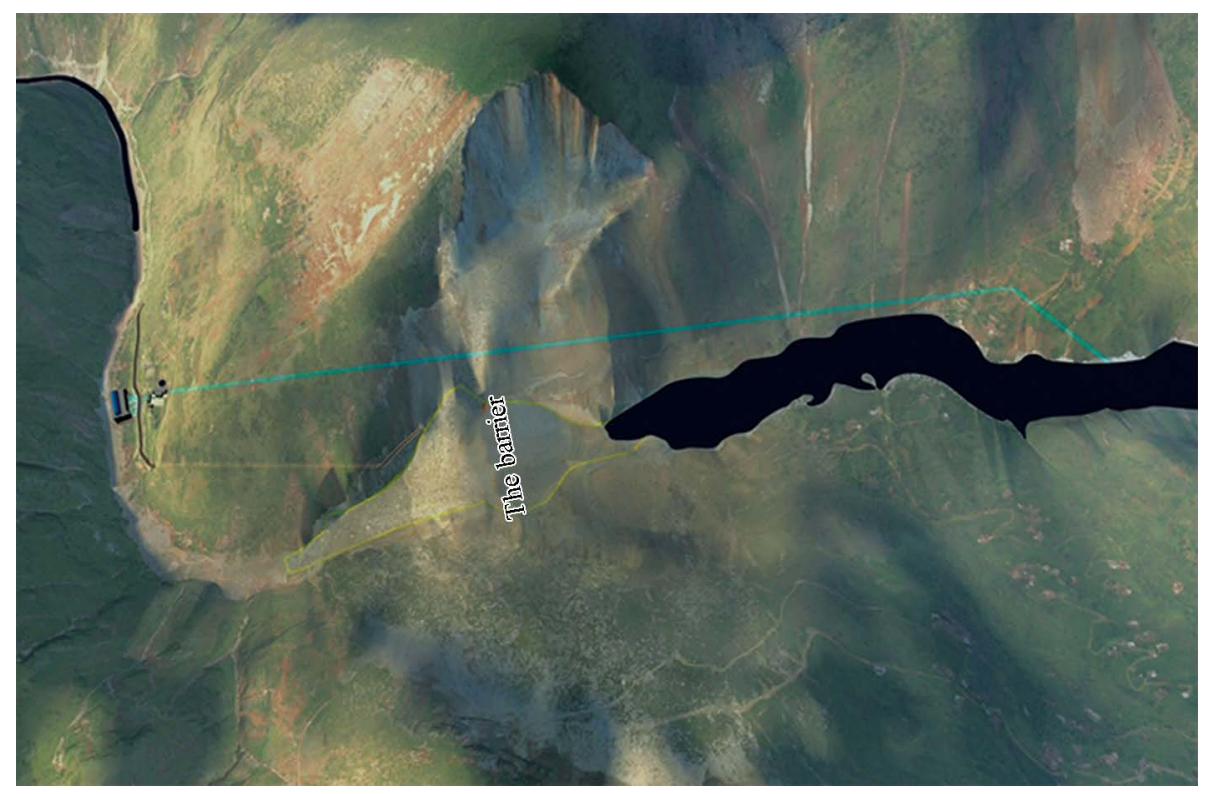

Figure 1. The position of the landslide dam and Hongshiyan hydro-power plant.

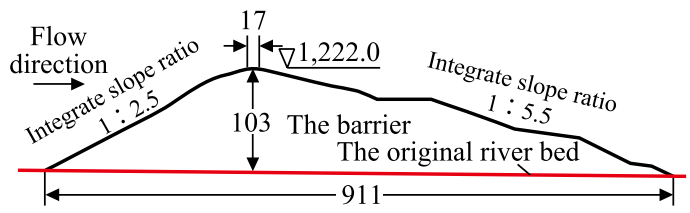

(a) Maximum profile of the landslide dam

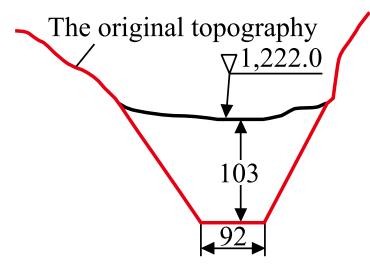

(b) Dam axis profile

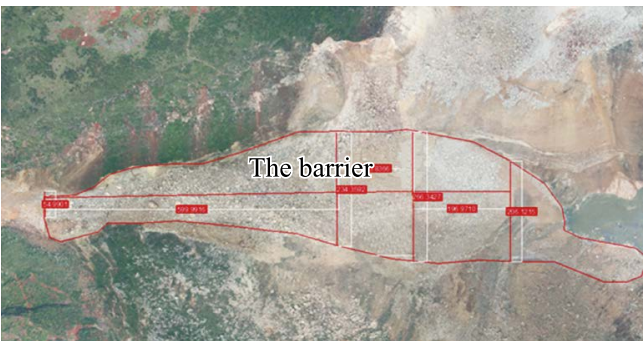

(c)

Figure 2. The typical section of Hongshiyan landslide dam (unit: m).

Table 1 Average Annual Flow Results of Hongshiyan Landslide Damsite

\begin{tabular}{|c|c|c|c|c|c|c|c|c|c|c|c|c|c|}
\hline Month & June & July & Aug. & Sept. & Oct. & Nov. & Dec. & Jan. & Feb. & Mar. & Apr. & May & Avg. \\
\hline Avg. flow $/\left(\mathrm{m}^{3} \cdot \mathrm{s}^{-1}\right)$ & 149 & 245 & 270 & 237 & 187 & 117 & 78 & 62.6 & 53.1 & 46 & 41.4 & 50.9 & 128 \\
\hline Ratio & $10 \%$ & $16 \%$ & $18 \%$ & $15 \%$ & $12 \%$ & $8 \%$ & $5 \%$ & $4 \%$ & $3 \%$ & $3 \%$ & $3 \%$ & $3 \%$ & $100 \%$ \\
\hline
\end{tabular}




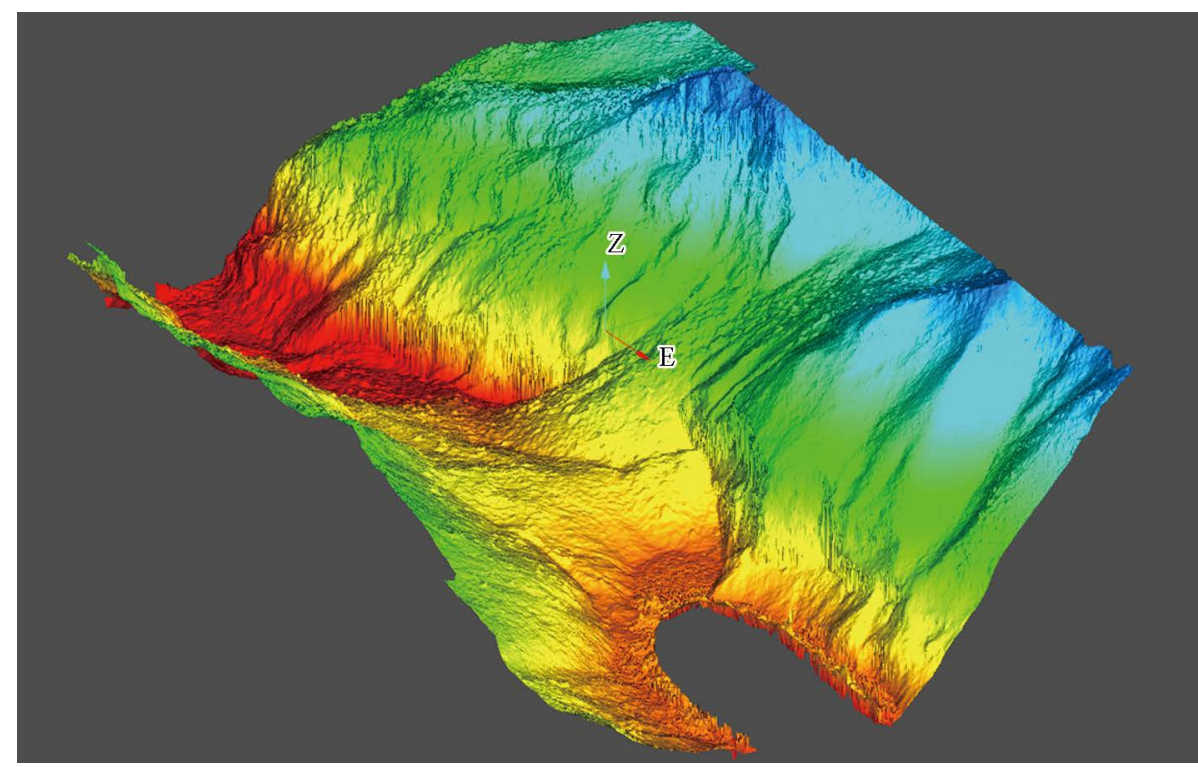

Figure 3. Three-dimensional topography model of Hongshiyan landslide dam.

to do their job at the same time at the same narrow site, making field operation extremely complicated.

\section{Danger removal plan}

\subsection{The principle of danger removal}

While the flow of Niulan River increased compared with days before the landslide dam was formed, it was much lower than the flows of various frequencies in the main flood period. If without engineering measures, the water level upstream the dam would rise fast when the inflow became greater. In order to eliminate the dam's threat to the area downstream as soon as possible, the principle was to prepare for the worst but strive for the best. The overarching guideline was to detain inflow upstream, increase discharge in the middle part, discharge downstream, avoid risks on the banks and step up supports. Both engineering and non-engineering measures must be used to eliminate dangers in a scientific, safe and fast manner.

\subsection{Plan drafting}

As per the opinion of Yunnan Provincial Earthquake Relief Headquarters, the work team from State Headquarters of Flood Control and Drought Relief and Yunnan Provincial Government set up a Danger Removal Headquarters of Niulan River Hongshiyan Landslide Dam. The headquarters mobilized a professional team to come up with the Report on Danger Removal of Hongshiyan Landslide Dam on Niulan River during Yunnan Ludian 803 Earthquake. Yunnan Provincial Earthquake Relief Headquarters gave an official approval to the report on August 6, the same day it was sub- mitted.

According to the report, non-engineering measures to be taken for danger removal are shown as follows.

(1) Residents' relocation was the top priority. Officials of towns, townships and villages were personally accountable for the safe relocation of every household under their administration.

(2) Reservoirs upstream the landslide dam were regulated to hold more water and minimize the flow into the lake, hence checking the water rising speed in the lake.

(3) Hydro-power plants downstream were regulated to increase discharge and save room for retaining the lake outflow.

(4) Meteorological and hydrological agencies were asked to increase the in-situ real-time monitor frequency, informing the danger removal process.

(5) A united technical experts' team was set up to optimize the danger removal technical plan based on the rate of progress and the real-time situation.

(6) The People's Armed Police and the local forces were mobilized to repair the roads to the landslide dam as soon as possible in order to resume transportation critical for emergency treatment.

Four engineering measures could be taken in order to check the water rising speed, gain more time for danger removal and consequently safeguard life and property downstream.

(1) A sluice channel was excavated in the center-left of the dam body. The planned initial size of the channel was $5 \mathrm{~m}$ of bottom width, $8 \mathrm{~m}$ of height and 1:1.5 of slope on both sides.

(2) The emergency gate near the plug of surge shaft construction adit of Hongshiyan hydro-power plant was removed. A construction adit of $9 \mathrm{~m} \times 8 \mathrm{~m}$ was set up near the surge shaft downstream the diversion tunnel; the plug of the 
construction adit was $20 \mathrm{~m}$ long; an emergency corridor of $\phi 1.8 \mathrm{~m}$ was in the plug with an emergency gate at the end. After the emergency gate was removed, the outlet can discharge water by $60 \mathrm{~m}^{3} / \mathrm{s}$ to $90 \mathrm{~m}^{3} / \mathrm{s}$.

(3) A finite blasting of the surge shaft was conducted to increase the free flow volume of the shaft and slow down water level rise upstream the dam body, gaining precious time for emergency treatment.

(4) Measures were taken to clean up the floatage that may clog the intake of the hydro-power plant.

\subsection{Effects of the danger removal plan}

As the overarching guideline was to detain inflow upstream, increase discharge in the middle part, discharge downstream, avoid risks on the banks and step up supports, all the treatment measures were implemented accordingly.

\subsubsection{Detain inflow upstream}

The Deze reservoir upstream the dammed lake was quickly deployed to check inflow to the lake, checking the rise speed and hence gaining time for threatened residents to evacuate and emergency measure to be implemented. The Deze reservoir retained over $6 \times 10^{7} \mathrm{~m}^{3}$ of water inflow at 08:00 am on August 12 local time, and even managed to transfer water to other catchment areas. The pressure of the emergency treat- ment was consequently eased.

\subsubsection{Increase discharge in the middle part}

Considering that the dam body was right between the intake dam upstream the Hongshiyan hydro-power plant and the powerhouse downstream, measures must be taken immediately so as to ease the blockage on the mainstream of Niulan River. The intake tunnel on the right bank was deployed so as to form an emergency discharge channel. In this way the water rise speed could be slowed down, giving time to evacuation and emergency treatment (see Figure 4).

Moreover, the army forces were mobilized to excavate a sluice channel of $5 \mathrm{~m}$ wide, $8 \mathrm{~m}$ deep and 1 1.5 slope at a relatively low place on the dam top. The People's Liberation Army (PLA) and the People's Armed Police worked around the clock, braving through aftershocks, rain and potential rock-slides from the severely damaged mountain sides. The channel was finished on August 12 right on schedule (see Figure 5).

\subsubsection{Discharge downstream}

In the event of dammed lake collapse, Tianhuaban and Huangjiaoshu hydro-power stations downstream would be damaged, dams possibly being flooded and causing disastrous domino effect. To prevent such a scenario from hap-

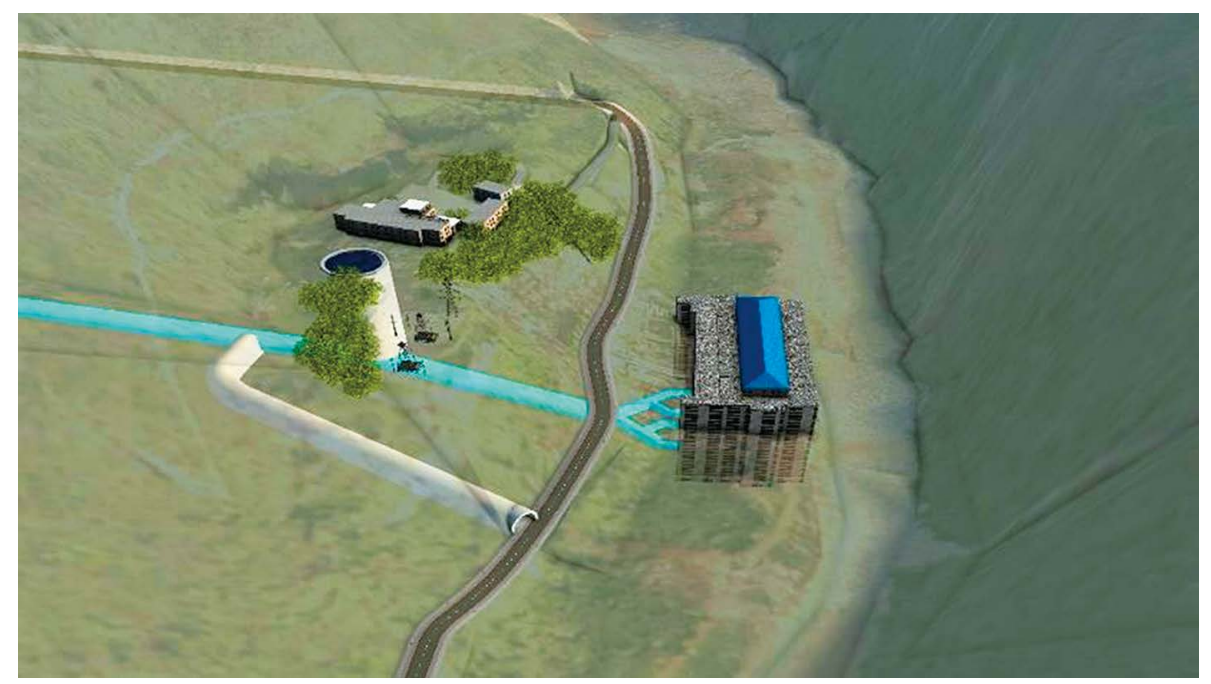

Figure 4. The location of the surge shaft and the construction adit of Hongshiyan hydro-power plant

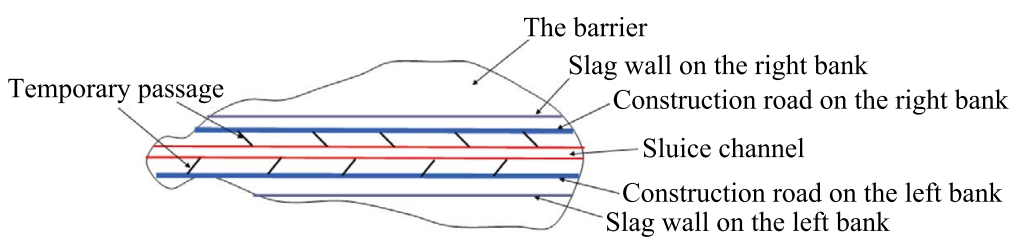

Figure 5. Sluice channel plan. 
pening, reservoirs downstream were pre-discharged in no delay. Tianhuaban and Huangjiaoshu reservoirs were lowered to the dead storage level, freeing up nearly $1 \times 10^{8} \mathrm{~m}^{3}$ of volume. At the same time, after calculations of Hongshiyan landslide dam collapse, emergency protection measures were taken in case of Tianhuaban dam overflowing, and reinforcement and behind-dam protection measures were taken at Huangjiaoshu in the case of deploying parapet walls for blocking flood.

\subsubsection{Avoid risks on the banks}

Residents along the river banks both upstream and downstream the Hongshiyan landslide dam had to be evacuated immediately in order to prevent casualty. Multiple organizations were involved in the analyses in consideration of the complexity of dam collapse. Kunming Engineering Corporation of Power China and China Institute of Water Resources and Hydro-power Research utilized IWHR-DB process to simulate Hongshiyan landslide dam collapse based on the dammed lake volume curve, field data as well as erosion characteristics of earth and rock-fill materials from Tangjiashan landslide dam analysis. The peak flow upon collapse was $6,110 \mathrm{~m}^{3} / \mathrm{s}$ and the duration was $6.24 \mathrm{~h}$. The Survey, Planning and Design Institute of Changjiang Water Resources Commission analyzed different collapse modes after the $8 \mathrm{~m}$ deep sluice channel was excavated. It was revealed that when the sluice channel was $8 \mathrm{~m}$ deep, the maximum flows upon full collapse, collapse by two thirds and by one third were $54,304 \mathrm{~m}^{3} / \mathrm{s}, 44,102 \mathrm{~m}^{3} / \mathrm{s}$ and $7,359 \mathrm{~m}^{3} / \mathrm{s}$, respectively. Inundation of the two reservoirs downstream was also calculated and water-surface profile and inundated water depth were provided; also, the relocation scope both upstream and downstream was identified in consideration of field data, safe free-board, distance, and potential geo-hazards. Altogether 12,797 threatened residents upstream and downstream were relocated, among which 3,548 lived upstream the dammed lake and 9,249 downstream.

\subsubsection{Step up supports}

(1) Step up transportation support. The key for danger remov$\mathrm{al}$ in the case of a landslide dam is for mechanical equipment and personnel to mount the barrier and get into the construction adit, making transport support paramount. Immediately after they reached the site, the People's Armed Police and the corps engineers of the PLA Thirteenth Army started cleaning up the landslide mass on the roads, excavating the slopes of broken rocks to build roads, and setting up ferrying rafts on the water surface. On August 6, a $2 \mathrm{~km}$-long waterborne transport line was completed, enabling the first mechanical equipment to get to the barrier and excavate the sluice channel around the clock. The hydro-power engineering troops of the armed forces miraculously managed to chisel out a 12kilometer-long "overhung road" out of the rock wall, creating advantageous conditions for the heavy construction ma- chines to get into the site. At the request of the Headquarters, the 14th Engineering Bureau of Power Construction Corporation of China (Power China) explored every possibility to dig out the emergency discharge channels. Some even risked their life to get into the surge shaft area of the powerhouse on August 8; regardless of the dangerous situation, they found the construction adit of the surge shaft and entered the tunnel where high-pressure flows were bursting around. There was only one chance for a successful blasting. The Headquarters and the on-site construction professionals worked out the plan while over 3 tons of explosives were delivered in the rain that very night to support the construction of emergency discharge channel on the right bank.

(2) Step up technical support. Experts from involved institutions launched on-site investigations, collected information, performed analysis and computation, and compared solutions to work out. In a very short period of time and with very limited resources, an "emergency treatment" plan within two days, which was submitted and approved in time. When it was close to the end of the emergency treatment, engineers stayed up late into the night to work on the "follow-up treatment" plan that included one main report (Safety Assessment and Follow-up Treatment Report on Risk Management of Hongshiyan Landslide Dam on Niulan River after Ludian 803 Earthquake in Yunnan Province) and three sub-reports (Safety Assessment Report on the Dam Body, Safety Assessment Report on Emergency Discharge Channels, and Report on the Impact of Flood upon Upstream and Downstream Area Caused by the Breach of Landslide Dam), forming the preliminary opinion for "follow-up treatment" that was submitted to and then approved by Yunnan Provincial Earthquake Relief Headquarters, and completing technical preparations for risk management and treatment in the immediate future.

(3) Step up logistics support. Being an important support for disaster relief and danger removal, logistics is indispensable for modern construction. In the process of emergency response and danger removal, the relevant local institutions not only gathered in time machine oil, explosives for construction blasting, drinking water, solid food, etc. for the disaster relief troops and the 14th Engineering Bureau of Power China, but also made great efforts in clearing the floatage upstream the landslide dam and ensuring the safety of construction blasting.

\section{Implementation process and effects}

3.1 Emergency discharge channel on the right bank were excavated within a short period of time

On August 6, the Danger Removal Headquarters of Niulan River Hongshiyan Landslide Dam entrusted the 14th Engineering Bureau of Power China with the task of excavating an emergency discharge channel on the right bank. Upon receiving the order, engineers of the bureau immediately 
started to work on the plans for removing the clog in both the construction adit of surge shaft for water diversion tunnel and the access tunnel, conducting construction survey and making preparations. On August 7, the surge shaft of the diversion tunnel started discharging flows larger than 100 $\mathrm{m}^{3} / \mathrm{s}$. On August 10, after days of repeated exploration and investigation in dangerous situations, with great obstacles of blocked roads, cover-up of debris flow and landslide, and severely damaged powerhouse, finite blasting was first conducted to the surge shaft, and then the emergency gate of construction adit was blasted and dismantled, resulting in an initial flow of about $80 \mathrm{~m}^{3} / \mathrm{s}$. With natural force of high-pressure flow, the discharge from the right-bank emergency channel gradually increased to over $320 \mathrm{~m}^{3} / \mathrm{s}$ on August 13 . (It was estimated that, as the water level of the dammed lake rose, the discharge volume could be larger.)

3.2 Efforts were sped up in excavating the sluice channel on top of the barrier

On August 6, the Danger Removal Headquarters of Niulan River Hongshiyan Landslide Dam entrusted the Hydro-power Engineering Troops of the Armed Police with the task of excavating a sluice channel on top of the barrier. On the same day, the waterborne transport line from the right bank to the barrier was ready for use. In the morning of August 7, the first excavator was sent to the barrier via ferrying rafts to start operation. On August 8, blasting and excavation were conducted to the boulders in the barrier. On August 9, the road from the left bank to the barrier was ready for use, and thanks to this road, many large machinery was able to be sent to the barrier. By $5 \mathrm{pm}$ on August 12, after 9 days of arduous efforts with $103,000 \mathrm{~m}^{3}$ of accumulative blasting excavation volume, the construction of the sluice channel was completed.

3.3 Monitoring, forecasting and warning were carried out in no time

Top-of-the-drawer resources and equipment of hydrological monitoring and early-warning were mobilized to the site, monitoring stations and professionals were added, lines of monitoring and forecasting were set up, communication channels were opened, visual monitoring in the rear was enabled, transmission frequency was encrypted, cooperation with meteorological departments was stepped up, and real-time monitoring and early-warning were enhanced to provide important support for evacuation and emergency response of landslide dam. Statistics show that in total 40 professional monitoring and forecasting experts were engaged in on-site monitoring, five emergency monitoring cross-sections were added upstream and downstream from the landslide dam, and two video monitoring systems were set up on the barrier, enabling reports of hydrological data every 30 minutes, video monitoring around the clock, and real-time forecasting when necessary.

\subsection{Effects and assessment}

\subsubsection{Effects}

With joint efforts, the emergency treatment was implemented as planned. Remarkable achievements were made, and all tasks were completed on schedule.

(1) Slowing down the rising speed of water level of the dammed lake. While the right-bank discharge channel was dug and expanded, reservoirs upstream the lake impounded the inflow and rainfall decreased, bringing down the rising speed of lake water level from $80 \mathrm{~cm} / \mathrm{h}$ in the beginning to less than $10 \mathrm{~cm} / \mathrm{h}$. Also, the water level even decreased to a stable level of $1,177 \mathrm{~m}$ to $1,181 \mathrm{~m}$ with regular inflow, gaining time for danger removal and evacuation.

(2) Reducing maximum storage capacity of the lake. The excavation of dam top sluice channel brought down the elevation of dam crest by $8 \mathrm{~m}$, reducing about $9 \times 10^{7} \mathrm{~m}^{3}$ of storage capacity and effectively reducing the risks of a dam collapse and the inundation of both the upstream and downstream areas.

(3) Evacuated people from the downstream area returned home. After the danger removal construction of the "emergency treatment" was finished, the scope of "risk area" and "alert area" in the downstream region was remarkably decreased. Under the conditions of setting strict security alert and making accountable responsibilities of the local governments, evacuated people from the downstream area were allowed to return home. After they returned, new evacuation plan should be made while flood warning and evacuation measures for the flood season prepared according to the new risk and alert areas. Namely, a water-level of $1,190 \mathrm{~m}$ in the dammed lake will trigger the state of flood control; a level at $1,200 \mathrm{~m}$ indicates a need to evacuate the people living in the risk area downstream; while a level of 1,208 $\mathrm{m}$ and a forecast of overflow scouring the barrier means that people living in the alert area need to be evacuated.

(4) Restoring transportation. The construction of rightbank water and land transportation as well as the left-bank road to the landslide barrier has laid a solid foundation for follow-up response and later-on treatment.

3.4.2 Assessment of danger removal measures and the results

\subsubsection{Assessment of danger removal measures}

(1) Safety assessment of the landslide barrier. Analysis and computation are conducted on the seepage, dam slope stability and deformation stability according to the technical codes (see Figure 6). The computation shows that, at or below the maximum water level of $1,222 \mathrm{~m}$, the stability of seepage, deformation and dam slope is up to the technical standards and the barrier is safe. However, in the case of a large inflow from the upstream area, the barrier will be overflowed and scoured from top to bottom, and prone to dam breach. 


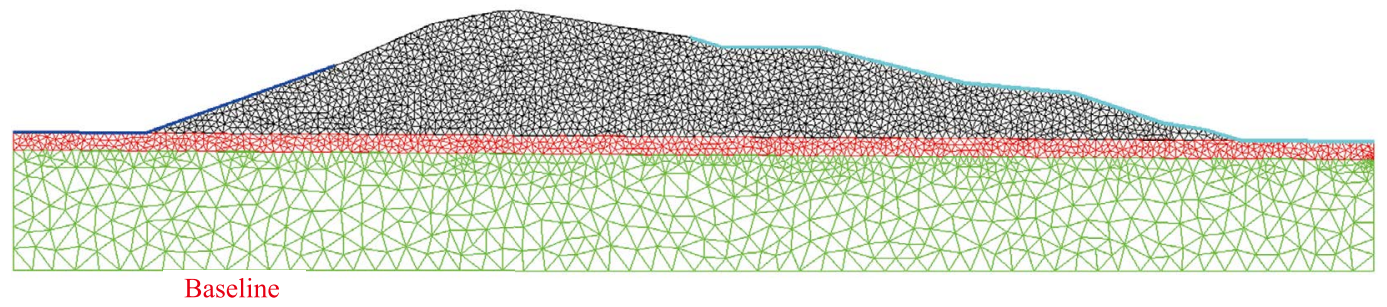

Figure 6. Finite element meshes of the maximum cross-section of the landslide barrier.

(2) Safety assessment of the emergency discharge channel. Recomputation is done on erosion resistibility of the discharge channels on top of the barrier and the structures of the right-bank diversion tunnels, surge shafts and construction adits. The computation shows that, the diversion tunnels are generally safe during the period of emergency response as well as follow-up treatment, and large-scale damage and collapse of lining will not appear. Diversion tunnels and surge shafts are safe to be used for discharge channels for the emergency response and later-on treatment. Judged from the block size of the elements that form the barrier, rock properties and weathering, it is estimated that the discharge channel can resist the erosion of a flow at the velocity of $3 \sim 4 \mathrm{~m} / \mathrm{s}$. In general, the erosion resistibility is quite high, and a sudden dam breach will not appear when overflowed. However, the unit discharge over the barrier should be minimized to reduce scouring.

(3) Capacity assessment of the emergency discharge channels. The emergency discharge channels include the surge shafts of diversion tunnels, the maintenance tunnels of construction adits and the discharge channels. Their capacities of discharge are shown in Figure 7.

Figure 7 indicates that, at a water level of $1,214 \mathrm{~m}$, the discharge capacity can reach $750 \mathrm{~m}^{3} / \mathrm{s}$, while at $1,222 \mathrm{~m}$ the capacity is $1,400 \mathrm{~m}^{3} / \mathrm{s}$, capable of discharging floods with a return period of five years (see Table 2).

\subsubsection{Assessment of the result}

In responding to the dangerous Hongshiyan landslide dam, full considerations were given to the cause and constituent elements of the landslide barrier, mechanical equipment and transportation, hydrological conditions and the scouring capacity of high-pressure flows. By excavating discharge channels, blasting surge shafts and the emergency gates of

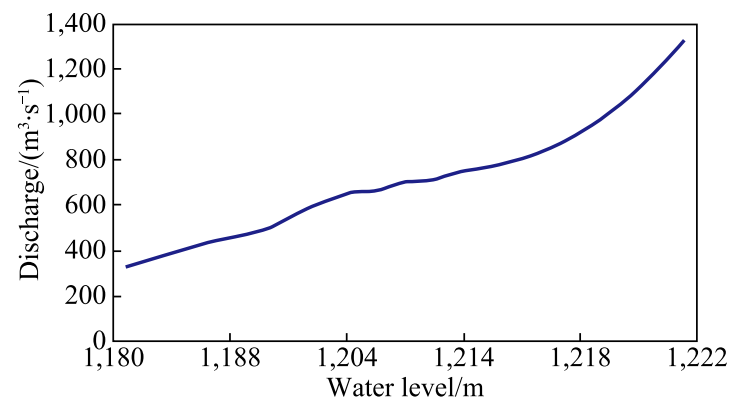

Figure 7. Discharge curve of the emergency discharge channels of Hongshiyan landslide dam.

construction adits, and making use of the scouring capacity of high-pressure flows to gradually increase the overflow capacity, the rising speed of water level upstream was decreased, and the water level upstream was even brought down to discharge the impoundment. It is proved that the concepts of adapting to the local conditions, taking actions according to the circumstances, and overall considerations were reflected in responding to the danger caused by Hongshiyan landslide dam. Based on the principles of being "scientific, safe and fast", objectives were achieved such as danger removal, the reduction of storage capacity, the discharge of impoundment, evacuated people returning home, and the considerations of both short-term and long-term needs.

\section{Cognition and thinking}

\subsection{Cognition on coordinated management}

Coordinated management consists of a range of acts including planning, organizing, directing, coordinating and con-

Table 2 The Design Flood of Hongshiyan Landslide Damsite

\begin{tabular}{lccccccccccc}
\hline Items & \multicolumn{10}{c}{ Results data } \\
\hline Rate $/ \%$ & 0.02 & 0.2 & 0.5 & 1 & 2 & 3.333 & 5 & 10 & 20 & 33.3 & 50 \\
Design flood $/\left(\mathrm{m}^{3} \cdot \mathrm{s}^{-1}\right)$ & 6,530 & 4,750 & 4,050 & 3,520 & 3,000 & 2,630 & 2,330 & 1,840 & 1,370 & 1,040 & 799 \\
One day flood volume $/\left(\times 10^{8} \mathrm{~m}^{3}\right)$ & 4.43 & 3.24 & 2.76 & 2.41 & 2.07 & 1.81 & 1.61 & 1.28 & \\
Three days flood volume $/\left(\times 10^{8} \mathrm{~m}^{3}\right)$ & 11.3 & 8.29 & 7.1 & 6.21 & 5.33 & 4.68 & 4.17 & 3.32 & \\
\hline
\end{tabular}


trolling, which are simultaneously carried out to deal with existing or potential management demands. Faced up to the whole-cycle development process of a system, based on the normal and non-normal horizons, and taken into full account of both the normal states and emergencies of the running system, coordinated management is thus needed to guarantee the sustained running, reduce operational risks, deal with emergencies and achieve the development goals of the system.

The successful treatment of the Hongshiyan landslide dam is an embodiment of the scientific concept of coordinated management in terms of its adaptability and effectiveness, and has become a good example of dealing with large landslide dams.

\subsubsection{Coordinating objectives of all phases}

According to the related national standards, landslide dam management can be divided into three phases specifying emergency treatment, follow-up treatment and later-on management. During the danger removal process of the Hongshiyan landslide dam, problems related to follow-up treatment were studied at the phase of emergency treatment by referring to the advantageous experiences in large-scale landslide dam management both domestically and abroad. Based on the specific situation of the Hongshiyan landslide dam, after repeated investigation by a technical team, the thought and plan of the follow-up treatment were then formed and the preliminary ideas of later-period management were put forward.

The main purpose of the follow-up treatment is to guarantee safety and reduce disasters, that is, to safeguard people's safety and minimize disaster-induced losses based on the outcome of the emergency rescue and safety assurance at the phase of emergency treatment, through further implementing engineering and non-engineering measures, raising flood control standards, and taking into full account of both realistic and feasible factors. Four measures were taken: first, expand the discharge channels both in depth and width to reduce the discharge per unit width and dam failure risk; second, further enhance the discharge capacity of the emergency discharge channels at the right bank of the dam, thus effectively lowering the water level of the dammed lake; third, further improve the early warning and forecasting mechanism for hydro meteorology to provide timely and efficient service during dammed lake treatment and for the relocation of people and the use of the hydro-power station; fourth, monitor the landslide dam and the surrounding areas in real time, to prevent potential landslides, debris flows, collapses and other secondary disasters, and encourage observation and preparedness by the public to avoid casualties, necessary safety measures must be taken to ensure construction safety at the phase of follow-up treatment. Due to the above measures taken during the follow-up treatment, the effects of the engineering measures at the emergency treatment phase can be further promoted, and the potential risks can be reduced. Besides, more advantages of follow-up treatment measures could also be seen, such as better controlling the water volume and level of the dammed lake, reducing uncertainty and increasing stability, and creating better conditions for improving the geological environment and mitigating the disaster impacts on the residents and hydro-power station upstream and downstream the dam, protecting the upstream Xiaoyantou power plant from being inundated, as well as initiating the operation of the downstream power plants and dams like Tianhuaban and Huangjiaoshu. All the above measures were put forward based on the results of the emergency treatment, and were deepened and extended as ones of the measures of the emergency treatment phase.

\subsubsection{Integrating endeavors from all sides}

A large number of diversified groups participated in the danger removal of Hongshiyan landslide dam, including experts from the State Flood Control and Drought Relief Headquarters and Changjiang Water Resources Commission, design personnel from the Kunming Engineering Corporation of Power China, and the local technical staff. At the construction site, there were people from the Corps of Electricity and Water of the People's Armed Police and the 14th Engineering Bureau of Power China. For traffic support, there were both Corps of Electricity and Water and Corps of Transportation of the People's Armed Police. As for logistics support, there were both local government and a great number of volunteers. All sides from the whole society have their own strengths and characteristics. For example, experts and scholars, having professional skills and technical advantages, were mostly relied on in making danger removal plans and carrying out site operation; the armed forces and corps of People's Armed Police, who were disciplined and quick in action, became the shock force in guaranteeing the safety of water traffic and the excavation of sluice channels at the dam crest; professional teams like the 14th Engineering Bureau of Power China, with strong technical skills and rich experience in executing construction, were the main force of breaking through the water diversion tunnel at the right bank to excavate the emergency discharge channels; staff of local government agencies, who knew better of the local conditions, made effective coordination and played a key part in providing logistics service; the large number of volunteers, who were models for collective participation, were the supportive force in providing logistics service and publicizing news and information. During the emergency management of Hongshiyan landslide dam, the different characteristics of various groups of people were fully considered, based on which their roles and responsibilities were clearly specified and divided and they themselves were managed by classification. Combining the endeavors from all sides and bringing their strengths into full play had reflected the principle of combining teamwork with rational mix of personnel, and it 
was an effective way of enhancing the efficiency of coordinated management by means of coordination and cooperation, the combination of specialists and masses, civil and military integration, as well as public participation.

\subsubsection{Making coordinated management strategies in a sys-} tematic way

While making strategies of coordinated management, we should not only consider risk management during the emergency phase, but also take into account of the demands of normal state. In other words, when the emergency treatment has been completed, the strategies that have been made should also be linked up with follow-up treatment, later-on management as well as post-disaster reconstruction. Therefore, coordinated management strategies must be made systematically by taking both short-term and long-term needs into consideration and making overall planning, thus to realize the optimization of resource utilization.

In normal circumstances, danger removal measures made for landslide dams are mostly to let the landslide body be scoured as soon as possible in a controllable state and to reduce water storage in the dammed lake to eliminate its danger. In the treatment of Hongshiyan landslide dam, there were six specific characteristics that must be considered. First, the landslide body was too large to be scoured and there was no space to hold such massive debris, and it would be costly to excavate all talus slide with a volume of $1.2 \times 10^{7} \sim 1.7 \times 10^{7} \mathrm{~m}^{3}$. Second, emergency discharge passages were formed during the emergency treatment phase, and discharge channels that could bear medium floods were excavated at the landslide body. Third, the landslide body was specially-shaped with a broad upstream surface (about $286 \mathrm{~m}$ long) and a narrow downstream surface (about $78 \mathrm{~m}$ long), the width ratio of which was $3.7: 1$, and it was a wedge-shaped body with a big front part and small back part. Fourth, the composition of the landslide materials made it difficult for the body to be scoured away or broken by low-flow overland flow at the dam crest. Fifth, according to the calculation analysis of the landslide body, the body would keep stable when there was no overland flow at the dam crest. Sixth, the main flood period had been halfway through when the emergency treatment was finished, and the water diversion measures that were taken for the Deze reservoir had saved enough storage capacity for the future one-month-long main flood period. Based on this, the main purpose of the later-on management was to mitigate disasters and bring benefits to the people, to make better use of the dammed lake by transforming it into a controllable reservoir and a multipurpose project combining a series of functions including irrigation, power generation, flood control, tourism, etc. The Hongshiyan dammed lake with a large storage capacity, if reconstructed into a reservoir, would play an important part in the regulation of the downstream cascade power plants of the Niulan River in terms of improving the efficiency of water resources utilization and power generation. As a consequence, while drafting and implementing measures for the emergency treatment phase, the phases of later-on management and post-disaster reconstruction must be considered all together. For example, the newly excavated water discharge tunnel with a length of $200 \mathrm{~m}$ and the cross section of $7.5 \mathrm{~m} \times 7.5 \mathrm{~m}$ was connected to the construction adit of the water diversion tunnel at the former plant. By a demolition blasting of the plug of the original construction adit, a new discharge passage was formed that could function as the construction diversion tunnel during rebuilding the landslide body into a dam. Besides, the deepened and widened sluice channel at the dam crest could also function as crest elevation after the reconstruction.

The endeavors made for danger removal at the Hongshiyan landslide dam had effectively reduced the risk of dam failure and narrowed the scope of downstream risk districts and warning districts, and the relocated people had returned home. However, as the flood risk of the dammed lake still remains, the local governments should make relocation and danger aversion plans according to the range of the newly designated risk districts and warning districts, put in place measures for flood warning and people transfer at the flood season, and strengthen supervision, inspection and accountability.

4.2 Thinking on capability improvement of coordinated management

In recent years, with the improvement of national governance capacity, China has made remarkable achievements and accumulated rich experience in coping with severe natural disaster emergencies like earthquake, mountain torrent, debris flow, local flood, etc., and the emergency response capability and the defensive system against disasters have been rapidly enhanced. In spite of this, the modern society is becoming more and more sensitive to emergencies and requires a higher level of management in dealing with those emergencies. In comparison, under the circumstances of social development and natural environment succession, the probability of emergencies' occurrence is increasing, which proposes a severer challenge and a higher demand to social management.

However, either the normal state management or emergency management based on traditional single management mode is no longer enough for meeting the challenge and demand above. Instead, we should combine some of the strategies in normal state management with some of those in emergency management, and make coordinated decisions to deal with any emergency in this constantly changing environment.

Therefore, we should endeavor to do the following: set up the idea that the reduction of disasters is social development, improve social resilience to systematic disasters and narrow the affected scope; revise policies and adjust systems in line with the vision of coordinated management; make reasonable plans in dividing regional functions and development goals by considering the natural and geographic features and the social-economic structures of the district, and using the 
thought of coordinated management; improve the mechanism of emergency management and the coordinated operation efficiency of existing systems; upgrade the planning system of coordinated treatment of emergencies, strengthen exercises to enhance the focalization and operability of the plan; carry forward the integration and interaction of public security information to realize information sharing; cultivate professional teams that could deal with both normal states and emergencies, thus compositing a unified and efficient force for any situation; promote the establishment of a scientific support system for coordinated management and the application of those scientific products; enhance publicity and education of disaster prevention and reduction to improve people's self-rescue and supportive ability. 